\title{
Synthesis of Nanostructured Anatase Mesoporous Membranes with Photocatalytic and Separation Capabilities for Water Ultrafiltration Process
}

\author{
Vahideh Tajer-Kajinebaf, ${ }^{1}$ Hossein Sarpoolaky, ${ }^{1}$ and Toraj Mohammadi ${ }^{2}$ \\ ${ }^{1}$ School of Metallurgy and Materials Engineering, Iran University of Science and Technology, Tehran 16846-13114, Iran \\ ${ }^{2}$ Research Laboratory for Separation Processes, Faculty of Chemical Engineering, Iran University of Science and Technology,
} Tehran 16846-13114, Iran

Correspondence should be addressed to Hossein Sarpoolaky; hsarpoolaky@iust.ac.ir

Received 14 December 2012; Accepted 26 January 2013

Academic Editor: Jiaguo Yu

Copyright ( 2013 Vahideh Tajer-Kajinebaf et al. This is an open access article distributed under the Creative Commons Attribution License, which permits unrestricted use, distribution, and reproduction in any medium, provided the original work is properly cited.

In this work, the nanostructured anatase mesoporous membranes were prepared for water ultrafiltration (UF) process with photocatalytic and physical separation capabilities. A macroporous substrate was synthesized from $\alpha-\mathrm{Al}_{2} \mathrm{O}_{3}$, then a colloidal titania sol was used for the preparation of the intermediate layer. Also, the membrane top layer was synthesized by deposition and calcination of titania polymeric sol on the intermediate layer. The characterization was performed by DLS, TG-DTA, XRD, BET, FESEM, TEM, and AFM techniques. Also, the filtration experiments were carried out based on separation of methyl orange from aqueous solution by a membrane setup with a dead-end filtration cell. Photocatalytic activity of the membranes was evaluated by methyl orange photodegradation using UV-visible spectrophotometer. The mean particle size of the colloidal and polymeric sols was 14 and $1.5 \mathrm{~nm}$, respectively. The anatase membranes exhibited homogeneity, with the surface area of $32.8 \mathrm{~m}^{2} / \mathrm{g}$, the mean pore size of $8.17 \mathrm{~nm}$, and the crystallite size of $9.6 \mathrm{~nm}$. The methyl orange removal efficiency by the mesoporous membrane based on physical separation was determined to be $52 \%$ that was improved up to $83 \%$ by a coupling photocatalytic technique. Thus, the UF membrane showed a high potential due to its multifunctional capability for water purification applications.

\section{Introduction}

Nowadays, due to the rapid industrialization, the demand for high-quality water has increased. The wastewater that usually consists of fine particles, microorganisms, or organic pollutants has seriously polluted the drain water [1]. Also, industrial dyes have been recognized as one of the largest sources of water contamination [2].

Physical separation technique is an effective technology for the removal of water pollutants. Compared with conventional treatment technology, membrane processes can provide easy operational control, low energy costs, potential material recovery, and more compact assembly $[3,4]$. However, the membrane's inherent shortcoming that the pollutants could merely be separated from water without further degradation makes it prone to cause secondary pollution. Thus, it needs to make an attempt with regard to its potential for degradation of pollutants to overcome the drawback of filtration [5].

Photocatalytic degradation of toxic organic compounds has received a great attention for the past several years [6]. Hence, removal efficiency of pollutants can increase by coupling photocatalytic technique with separation process. Separation and photocatalytic processes can be promising technologies for the purification of wastewater. These processes can be coupled together to produce photocatalytic membranes [7, 8]. Among different materials for this object, titania has received significant attention due to its high water flux, chemical stability, high photocatalytic activity $[9,10]$, strong oxidizing power, cost effectiveness, long-term stability, and especially energy band edges, which well match the redox potentials of water [11]. These properties cause promising application of titania membranes for water treatment [12, 13]. Although titania has been known as the most effective 


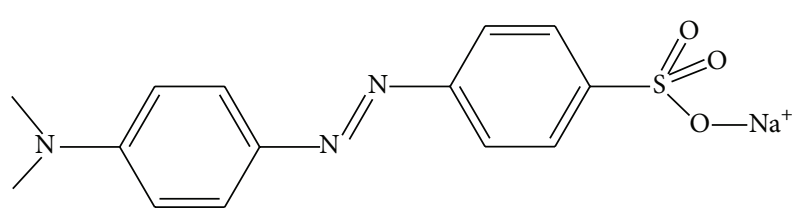

FIGURE 1: Chemical structure of methyl orange.

material for these objects, among different forms of titania, anatase is the most photoactive one [14-16]. Stabilization of anatase phase with high effective surface area is an important object in the synthesis process of titania membranes. Studies show the sol-gel method such as colloidal and polymeric ones can be a suitable route for the synthesis of the nanostructured anatase membranes with high effective surface area $[7,8,17]$.

In the present work, the nanostructured anatase membranes were prepared by deposition and calcination of the polymeric titania sol on the colloidal titania-coated alumina substrates and then were characterized by DTA-TG, XRD, FESEM, TEM, AFM, BET, and UV-Vis spectroscopy. Also, the photocatalytic and separation capabilities of the mesoporous anatase membranes were evaluated by the determination of the removal efficiency of methyl orange based on its concentration changes in aqueous solution.

\section{Experimental Procedures}

2.1. Materials. Granulate powder of $\alpha-\mathrm{Al}_{2} \mathrm{O}_{3}$ (KMS-92, Martinswerk) with chemical composition shown in Table 1 was chosen as raw material for the preparation of the membrane substrate.

Titanium tetraisopropoxide (TTIP, Merck 821895), isopropanol (IPA, Merck 109634), nitric acid (65\% solution, Merck 100456), hydrochloric acid (37\% solution, Merck 100317), and deionized water as raw materials as well as hydroxypropyl cellulose (HPC, Aldrich 435007) and polyvinyl alcohol (PVA, Acros 821038) as binders were used for the preparation of the colloidal and polymeric titania sols. Methyl orange (MO, Merck 101322) with chemical formula of $\mathrm{C}_{14} \mathrm{H}_{14} \mathrm{~N}_{3} \mathrm{NaO}_{3} \mathrm{~S}$ (see Figure 1) and molar mass of $327.34 \mathrm{~g} / \mathrm{mol}$ was used as the model pollutant for investigation of photocatalytic decolorization and separation capabilities of the synthesized anatase membranes.

\subsection{Membrane Preparation}

2.2.1. Alumina Substrate. To prepare the membrane substrate, $\alpha-\mathrm{Al}_{2} \mathrm{O}_{3}$ granulate powder was shaped into a disk with $17 \mathrm{~mm}$ in diameter and $2 \mathrm{~mm}$ in thickness using a uniaxial press under the pressure of $150 \mathrm{psi}$. The sintering process was carried out with a heating rate of $10^{\circ} \mathrm{C} / \mathrm{min}$ up to $1000^{\circ} \mathrm{C}$ and was then followed with a rate of $5^{\circ} \mathrm{C} / \mathrm{min}$ up to $1380^{\circ} \mathrm{C}$. Also, the retention time at the maximum temperature was set to be $1 \mathrm{~h}$.

2.2.2. Membrane Interlayer. The membrane interlayer was prepared by the deposition of the colloidal titania sol on
TABLE 1: Chemical composition of $\alpha-\mathrm{Al}_{2} \mathrm{O}_{3}$ powder.

\begin{tabular}{lcccccc}
\hline Oxides & $\mathrm{Al}_{2} \mathrm{O}_{3}$ & $\mathrm{SiO}_{2}$ & $\mathrm{CaO}$ & $\mathrm{MgO}$ & $\mathrm{Fe}_{2} \mathrm{O}_{3}$ & $\mathrm{Na}_{2} \mathrm{O}$ \\
\hline Weight (\%) & 92 & 3.6 & 2.5 & 1.5 & $<0.2$ & $<0.1$ \\
\hline
\end{tabular}

the alumina substrate. The colloidal sol was obtained by hydrolysis of TTIP via the addition of an excess $\mathrm{H}_{2} \mathrm{O}$ $\left(\left[\mathrm{H}_{2} \mathrm{O}\right] /[\mathrm{Ti}]>4\right)$. A solution of TTIP in IPA was added dropwise to a solution of water in IPA while stirring at high speed. Then, the alcohol was removed from the solution by rotary system and the washed product was dispersed in water to achieve the $\mathrm{Ti}$ concentration to $0.4 \mathrm{~mol} / \mathrm{lit}$. The solution was peptized with acid by adjusted $\mathrm{pH}$ to 1.5 and was refluxed at about $70^{\circ} \mathrm{C}$ for $20 \mathrm{~h}$, which resulted in a semiopaque titania dispersion. Then, the sol was poured in beaker glass and subsequently was held for $30 \mathrm{~min}$ in an ultrasonic bath to break the weakly agglomerated particles. Finally, a clear blue stable sol was obtained. Consequently, a solution of HPC and PVA was added to the obtained sol as binder. For applying the titania layer, the colloidal sol was deposited on the alumina substrate for four steps by dipcoating process at a constant rate of $6 \mathrm{~mm} / \mathrm{min}$ and immersion time of $30 \mathrm{~s}$. Also, the unsupported gel layer was prepared by pouring the colloidal sol in a petri dish. Both the supported and unsupported gel layers were dried at room temperature for $48 \mathrm{~h}$ then were heat-treated at different temperatures for $1 \mathrm{~h}$ with a heating rate of $1^{\circ} \mathrm{C} / \mathrm{min}$. Finally, the colloidal titania-coated alumina substrates were prepared.

2.2.3. Membrane Top Layer. Membrane top layer was prepared by the deposition of polymeric titania sol on the intermediate layer. First, the polymeric sol was obtained by hydrolysis of TTIP via the addition of a less than equivalent amount of $\mathrm{H}_{2} \mathrm{O}\left(\left[\mathrm{H}_{2} \mathrm{O}\right] /[\mathrm{Ti}]<4\right)$ in order to obtain a precipitatefree polymeric sol. A solution of water and hydrochloric acid as a catalyst in IPA was added dropwise to a solution of TTIP in IPA during high speed stirring. The molar ratio for TTIP : IPA : $\mathrm{H}_{2} \mathrm{O}: \mathrm{HCl}$ of the final sol was $1: 31: 0.8: 0.23$, respectively. Stirring was continued for $4 \mathrm{~h}$ to get a stabilized sol. Finally, the obtained transparent sol was deposited on the colloidal titania-coated alumina substrates for four steps by dip-coating process with a constant rate $6 \mathrm{~mm} / \mathrm{min}$ and time immersion of $30 \mathrm{~s}$. Also, the unsupported gel layer was prepared by pouring the polymeric sol in a petri dish. The supported and unsupported polymeric titania gel layers were dried at room temperature for $24 \mathrm{~h}$. Finally, heat treatment was done at different temperatures for $1 \mathrm{~h}$ with a heating rate of $1^{\circ} \mathrm{C} / \mathrm{min}$.

2.3. Characterization. The substrate porosity was measured according to the ASTM C373-88 standard by the Archimedes method. The mechanical strength of the substrate was measured according to ASTM C1505-01 by SANTAM universal testing machine, STM-400 series. Particle size distribution of the prepared colloidal and polymeric titania sols was determined by dynamic light scattering technique (DLS, ZS3600, Malvern). Thermal properties of the dried gels were characterized by thermogravimetry and differential 
TABLE 2: The optimized preparation conditions and the properties of alumina substrates.

\begin{tabular}{lccccccc}
\hline \multirow{2}{*}{ Material } & \multicolumn{2}{c}{ Size } & Pressure & Heat treatment & Strength & Pore diameter $^{*}$ AWA $^{1}$ & MOP $^{2}$ \\
& Diameter & Thickness & & & & & \\
\hline$\alpha-\mathrm{Al}_{2} \mathrm{O}_{3}$ & $17 \mathrm{~mm}$ & $2 \mathrm{~mm}$ & $150 \mathrm{psi}$ & $1380^{\circ} \mathrm{C}, 1 \mathrm{~h}$ & $38 \mathrm{MPa}$ & $1-3 \mu \mathrm{m}$ & $15 \%$ \\
\hline
\end{tabular}

${ }^{1}$ Average water absorption. ${ }^{2}$ Mean open porosity.

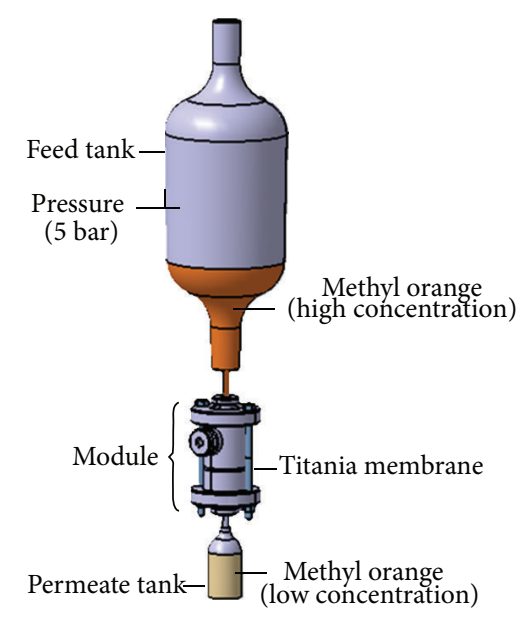

FIGURE 2: Schematic image of a membrane setup with a dead-end filtration cell used for filtration experiments.

thermal analysis (TG-DTA, PERKINELMER) in a nitrogen flow with a heating rate of $7.5^{\circ} \mathrm{C} / \mathrm{min}$ up to $900^{\circ} \mathrm{C}$. The phase composition and the average crystallite size of the membranes were identified using X-ray diffraction technique with $\mathrm{Cu} \mathrm{K} \alpha$ wavelength (Philips PW1800). The morphology of the samples was characterized by field emission scanning electron microscopy (FESEM, WEGA $\backslash \backslash$ TESCAN) and transmission electron microscopy (TEM, EM 208, Philips) with an accelerating voltage of $30 \mathrm{kV}$ and $100 \mathrm{kV}$, respectively. Surface roughness and morphology of the prepared membranes were evaluated by atomic force microscopy (AFM, DualScope C26, DME). Also, $\mathrm{N}_{2}$-sorption measurements (Belsorp mini II, BEL Japan, Inc.) were performed to determine the BrunauerEmmett-Teller (BET) surface area and the pore size of the membrane top layer. The separation experiments were carried out using a membrane setup with a dead-end filtration cell under 5-bar pressure according to Figure 2.

Moreover, the feed solution containing $20 \mathrm{mg} / \mathrm{L}$ of MO aqueous solution was transported through membrane module, and then concentration of the permeate solution was determined by recording UV-Vis absorption spectra using UV-visible spectrophotometer (Agilent, 8453). Also, the photocatalytic activity of the membranes was measured by the photodegradation of MO aqueous solution. The prepared membrane in an $\mathrm{MO}$ solution $(20 \mathrm{mg} / \mathrm{L})$ was irradiated by a UV source (Sunny, 360-415 nm, 125 W), and then removal efficiency was evaluated by determination of concentration changes of MO solution by UV-visible spectrophotometer. Also, water permeation measurements were carried out using the as-prepared membrane setup. The feed side of the membrane was kept at a constant pressure of 5 bar and the permeate side was set at atmospheric pressure. The permeation flux was measured at room temperature using the following [18]:

$$
\text { Permeation flux }=\frac{Q}{A} \cdot \Delta t
$$

where $Q$ is the quantity of permeate $\left(\mathrm{cm}^{3}\right), A$ is the effective membrane area $\left(\mathrm{m}^{2}\right)$, and $\Delta t$ is the sampling time (h). Effective area of the membrane in the module was $1.76 \mathrm{~cm}^{2}$.

\section{Results and Discussion}

3.1. Substrate. Alumina was chosen as a membrane substrate due to high chemical stability in acidic and basic environment $[19,20]$. FESEM images of the surface and cross-section of the prepared $\alpha-\mathrm{Al}_{2} \mathrm{O}_{3}$ substrate are shown in Figure 3 .

Based on FESEM results, the distribution pore size of the alumina substrate is in the range of $1-3 \mu \mathrm{m}$ that can be a macroporous substrate according to IUPAC [21]. The support pore size should be large enough to build a pore size gradient from the support through the membrane layer. The gradient in the pore size effectively prevents early clogging of the membrane during its performance [7]. The mechanical strength of the substrate was determined to be $38 \mathrm{MPa}$ according to the three-point bending test. Also, the mean open porosity and average water absorption of the substrate were determined to be $40 \%$ and $15 \%$, respectively. The optimized preparation conditions as well as the properties of alumina substrates are given in Table 2.

\subsection{Membrane Interlayer}

3.2.1. Particle Size Distribution. Particle size distribution of the colloidal titania sol according to Figure 4 is in the range of 9-50 nm with a mean particle size of $14 \mathrm{~nm}$.

In colloidal sol-gel route due to the presence of excess water, hydrolysis occurs fast and leads to the formation of relatively large particles that can easily cover the surface of alumina substrates without infiltration.

3.2.2. Thermal Analysis. The thermogravimetry and differential thermal analysis were used to obtain qualitative and quantitative information about the effects of heat treatment on the colloidal titania such as the combustion temperature of the organic compounds and the decomposition of hydroxyl groups as well as to determine the optimum calcination temperature of the intermediate layer. DTA-TG curves of the dried colloidal titania gel are given in Figure 5. 


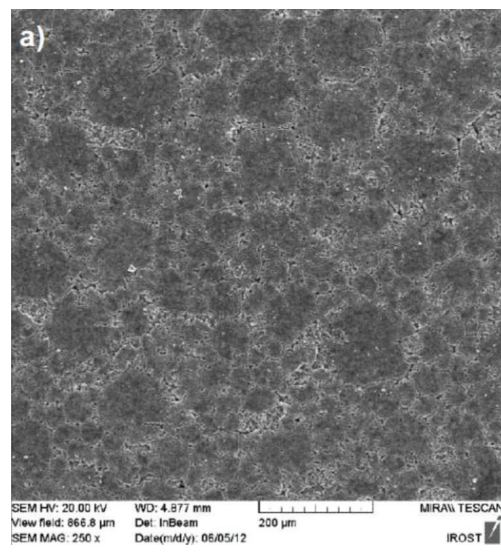

(a)

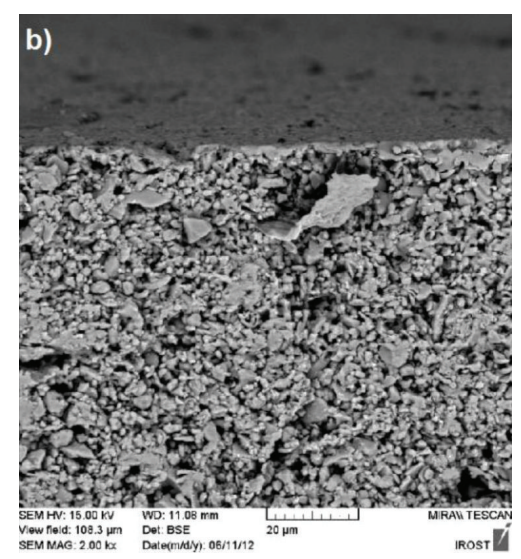

(b)

FIGURE 3: FESEM images of the (a) surface and (b) cross-section of the alumina substrate.

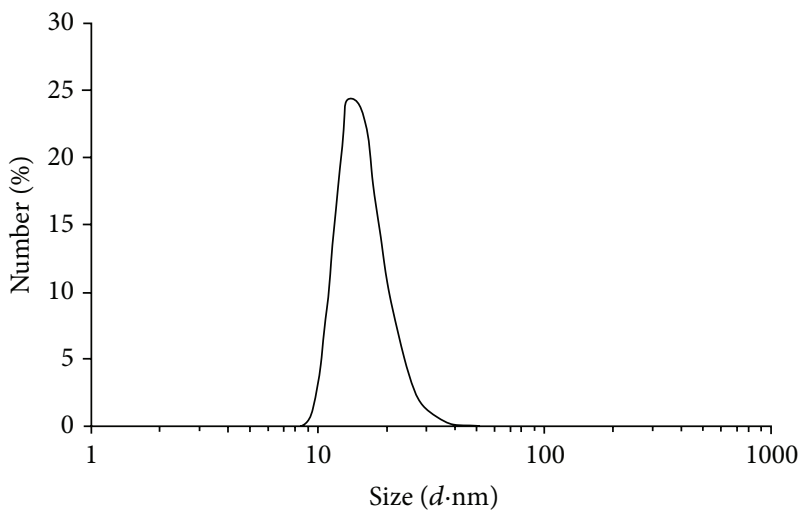

FIgURE 4: Particle size distribution of the colloidal titania sol.

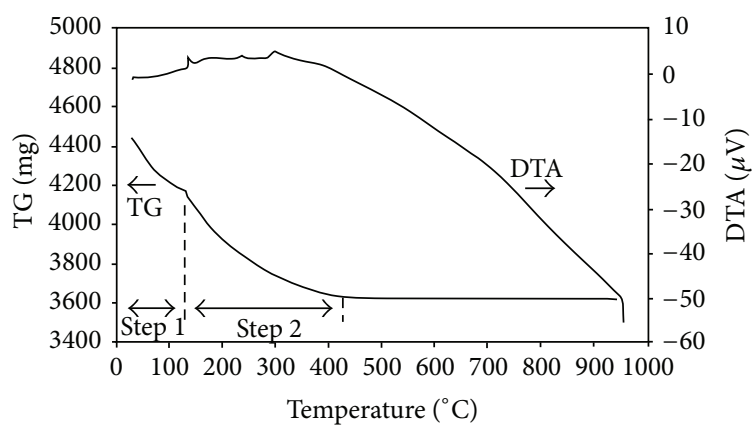

FIGURE 5: The thermogravimetry and differential thermal analysis of the dried colloidal titania gel.

According to Figure 5, the thermogravimetric curve follows $19 \%$ weight loss during two steps. The first step extends up to about $130^{\circ} \mathrm{C}$ that is attributed to the removal of adsorbed water corresponding to endothermic peak [22-24]. The second step extends up to $420^{\circ} \mathrm{C}$ that is according to the expulsion of organics and the dehydroxylation of $\mathrm{Ti}(\mathrm{OH})_{4}$. This step is along with $\mathrm{TiO}_{2}$ phase transition according to exothermic peaks at 220 and $300^{\circ} \mathrm{C}$. The former corresponds

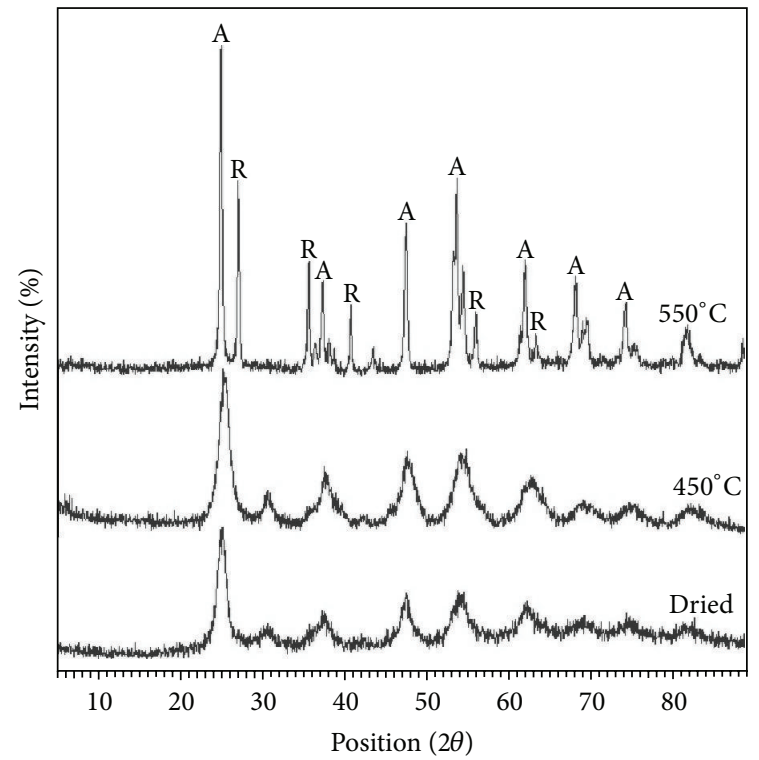

A: Anatase
R: Rutile

FIGURE 6: XRD patterns of the dried and calcined colloidal titania gels.

to the removal of organics and the latter can be due to phase transition from amorphous to anatase. Finally, the weight loss ends at about $420^{\circ} \mathrm{C}$ which can be a minimum calcination temperature for intermediate layer according to the complete removal of the organics.

3.2.3. Phase Analysis. The XRD patterns of the dried and calcined colloidal titania gels are shown in Figure 6. The strongest peaks of anatase and rutile phases are located at $2 \theta=25.3^{\circ}$ (101) and $27.4^{\circ}(110)$, respectively [25].

According to Figure 6, phase structure of the dried colloidal titania gel is anatase while during calcination and by increasing the temperature, anatase peaks become sharper 
and then rutile peaks are formed. Based on XRD results, at $450^{\circ} \mathrm{C}$, titania is fully crystalline in the anatase form while rutile phase peaks are seen at $550^{\circ} \mathrm{C}$. Several factors should be considered to select an optimum temperature for the calcination of membrane interlayer. First, the organic additives and hydroxyl groups should be completely removed and, second, titania should remain in the anatase form with a minimal crystallite size. Based on XRD and TG-DTA results as well as considering the above factors, the calcination of the intermediate layer was carried out at $450^{\circ} \mathrm{C}$ for $1 \mathrm{~h}$. Also, a low heating rate $\left(1^{\circ} \mathrm{C} / \mathrm{min}\right)$ was chosen to prevent cracking of the interlayer during sintering process.

3.2.4. Microstructural Analysis. The top surface and crosssection FESEM images of the colloidal titania-coated alumina substrates are shown in Figure 7.

According to Figure 7(a), it can be seen that the surface of the alumina substrate is completely covered with the colloidal titania, implying that a continuous layer was formed on the surface. Also, it can be estimated that the thickness of the colloidal titania layer is about $2.5 \mu \mathrm{m}$ (see Figure 7(b)). Our researches showed that the layer thickness increases with increasing the sol concentration and the dipping steps. Although few researchers mentioned that addition of PVA is sufficient for dipping solution [26, 27], others added both HPC and PVA to colloidal sol for dipping process $[7,28]$. Alem et al. reported that PVA as a single additive that causes flocculation of the titania sol, but in combination with HPC no flocculation occurs. HPC hinders the interaction between PVA and titania and therefore can prevent flocculation of the sol. Also, Sekulić-Kuzmanović reported that a high PVA content causes flocculation of the colloidal titania sol, and a high HPC content decreases the viscosity of sol [29]. In the present work, a crack-free layer was achieved by addition of both HPC and PVA additives to the colloidal titania sol during four-step coating with the dipping time of $30 \mathrm{~s}$. Therefore, the drying process was performed in a high humidity atmosphere, and then calcination process was carried out at an optimized temperature of $450^{\circ} \mathrm{C}$ for $1 \mathrm{~h}$ with a low heating rate of $1^{\circ} \mathrm{C} / \mathrm{min}$.

3.2.5. AFM Analysis. AFM micrographs showing the surface morphology of the colloidal titania-coated alumina substrate are given in Figure 8.

Figure 8 shows that the surface is quite rough at the micrometer scale, with a granular structure consisting of interconnected grain particles. The particles build up high mountains and deep valleys that seem to allow a better ability to absorb membrane top layer.

\subsection{Membrane Top Layer}

3.3.1. Particle Size Distribution. As shown in Figure 9, the particle size distribution of the polymeric titania sol is in the range of $1-3 \mathrm{~nm}$ with the mean particle size of $1.5 \mathrm{~nm}$.

The polymeric titania sol has much smaller particles (nanometer-sized) compared to the colloidal one (see Figure 4). Thus, the deposition of the polymeric titania sol on
TABLE 3: Phase analysis results of the polymeric titania membrane at different calcination temperatures.

\begin{tabular}{lccc}
\hline Temperature $\left({ }^{\circ} \mathrm{C}\right)$ & 450 & 550 & 650 \\
Phase & Anatase & Anatase & Anatase \\
Crystallite size $(\mathrm{nm})$ & 9.6 & 15.8 & 31.8 \\
\hline
\end{tabular}

the colloidal titania-coated substrate could produce a defect free top layer with the small pore size.

3.3.2. Thermal Analysis. The thermogravimetric and DTA curves of the dried polymeric titania gel are given in Figure 10.

The thermogravimetric curve follows $45 \%$ weight loss during three steps. The first step that extends up to $210^{\circ} \mathrm{C}$ can be attributed to the removal of alcohol and adsorbed water [29]. The second step to $250^{\circ} \mathrm{C}$ corresponds to removal of isopropoxy groups $\left(-\mathrm{OC}_{3} \mathrm{H}_{7}\right)$ [29] and the third step that extends up to $440^{\circ} \mathrm{C}$ is attributed to the dehydroxylation of $\mathrm{Ti}(\mathrm{OH})_{4}$. Also, the board exothermic peak seen in DTA curve can be attributed to $\mathrm{TiO}_{2}$ phase transition from amorphous to anatase. Based on TG curve, the weight loss beyond $440^{\circ} \mathrm{C}$ is negligible that is in agreement with the literature [29]. No significant thermal effects of the anatase-rutile transformation are detected up to $900^{\circ} \mathrm{C}$.

3.3.3. Phase Analysis. According to Figure 11, XRD patterns of the polymeric titania show only anatase phase at different calcination temperatures.

The crystallite size of the prepared anatase membranes at different calcination temperatures was determined by Scherrer's equation $[30,31]$ of which results are recorded in Table 3.

The highest photocatalytic activity of titania is seen in the anatase form with optimal crystallite size in the range $8-10 \mathrm{~nm}$ [32]. Moreover, titania calcined at $450^{\circ} \mathrm{C}$ shows the fully crystalline anatase phase with the crystallite size of $9.6 \mathrm{~nm}$. Thus, based on TG-DTA and XRD results, $450^{\circ} \mathrm{C}$ temperature was selected as an optimum temperature for calcination of the membrane top layer. However, the low calcination temperature of titania makes it possible to prepare membranes with the reduced pore and crystallite sizes [7].

3.3.4. Microstructural Study. Figure 12 shows the FESEM micrographs of the cross-section and top surface of the synthesized anatase membranes. As shown, a crack-free anatase layer with the thickness of about $0.5 \mu \mathrm{m}$ is formed on the top surface of the colloidal titania-coated alumina substrate.

It is important to control the thickness of membrane top layer which has a significant effect on membrane permeability. The increasing thickness of top layer decreases membrane permeability as well as increases probability cracking during drying and calcination steps. Also, an optimum thickness provides better photocatalytic activity and overcomes the 


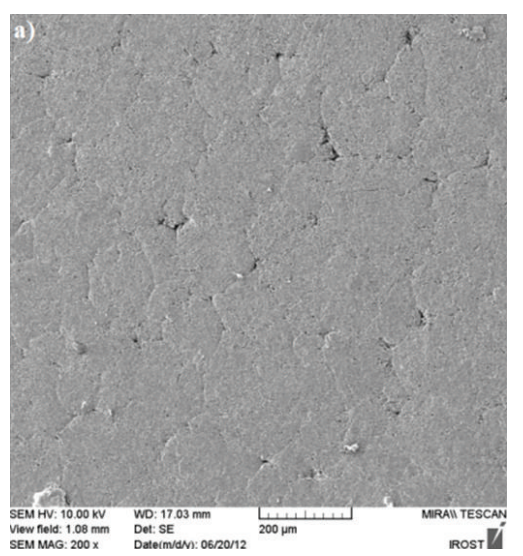

(a)

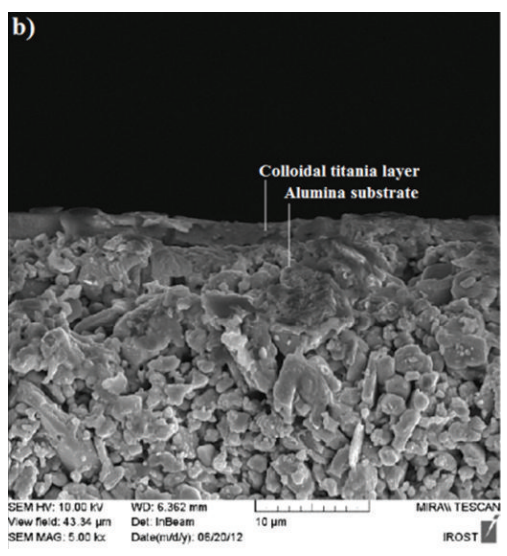

(b)

FIGURE 7: The FESEM images of the (a) top surface and (b) cross-section of the colloidal titania-coated alumina substrates.

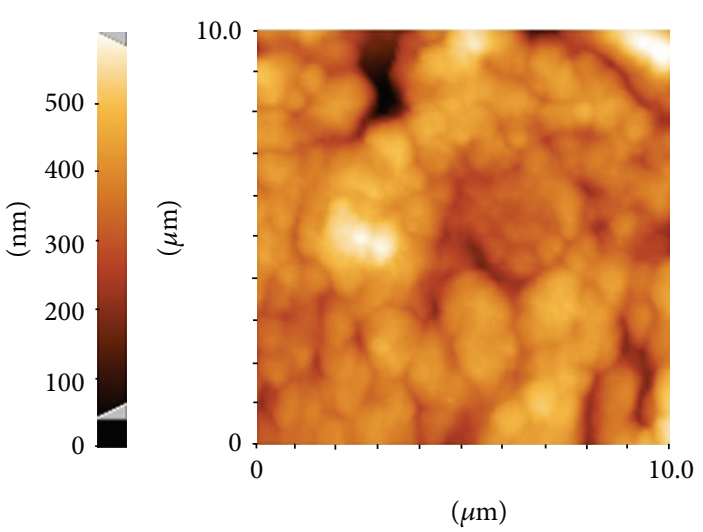

(a)

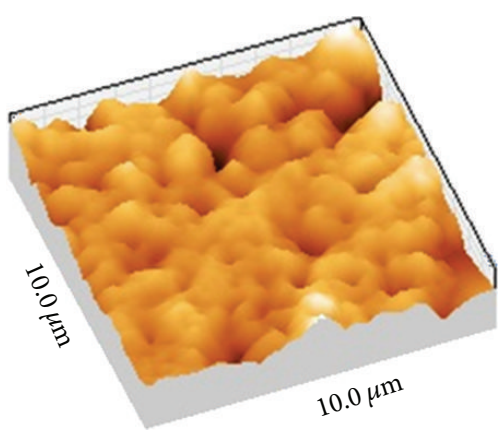

(b)

FIGURE 8: AFM micrographs (a) 2D and (b) 3D of the surface morphology of the colloidal titania-coated alumina substrate.

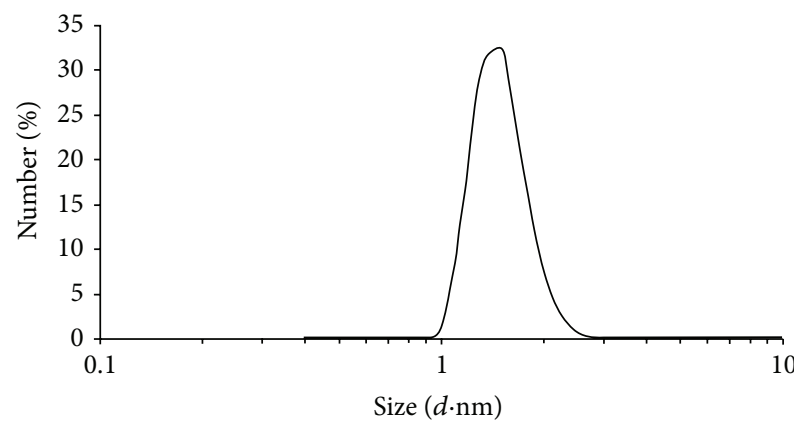

FIgUre 9: Particle size distribution of the polymeric titania sol.

irregularities and roughness of the surface. Our observations indicated that is increasing time and number of dipping steps increases top layer thickness. In the present study, an optimum thickness (about $500 \mathrm{~nm}$ ) was obtained with fourstep coating and dipping time of $30 \mathrm{~s}$.

Also, TEM images in Figure 13 show that the membrane top layer consists of large particles that are agglomerations of smaller particles in nanometer scale $(10-20 \mathrm{~nm})$. Also, it

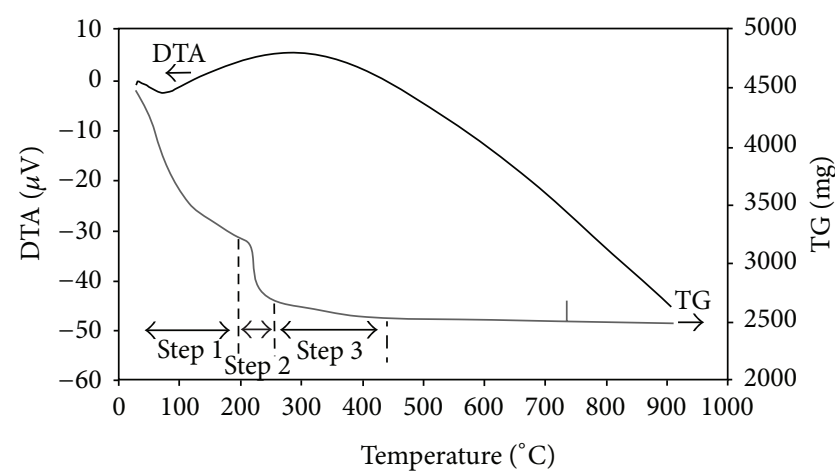

FIgURE 10: The thermogravimetric and DTA curves of the dried polymeric titania gel.

can be observed that crystallites are isotropic. According to Figure 13, the nanoparticles are well crystallized that are in agreement with XRD results.

3.3.5. AFM. AFM micrographs of surface morphology of the prepared anatase membrane are shown in Figure 14. 


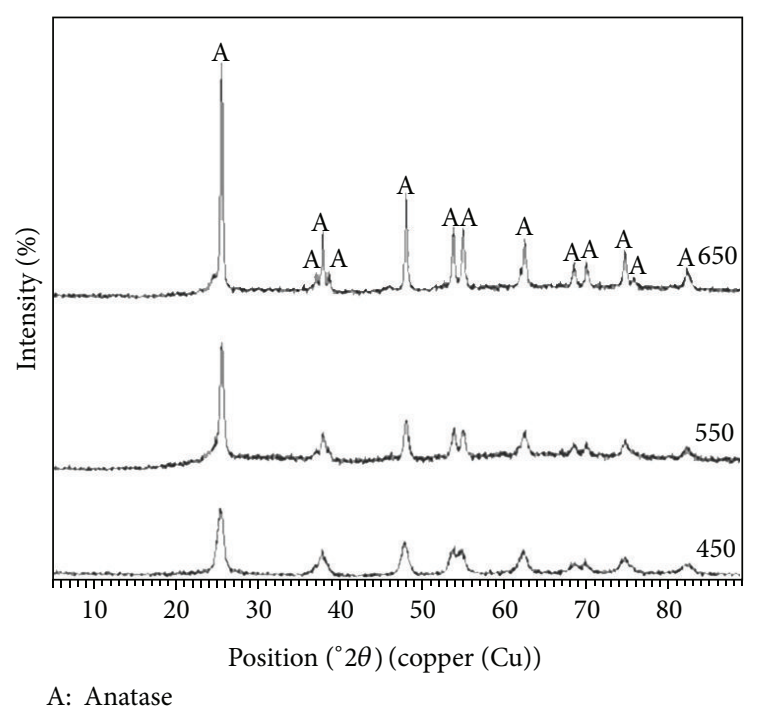

FIGURE 11: XRD patterns of the unsupported polymeric titania membranes at different calcination temperatures.

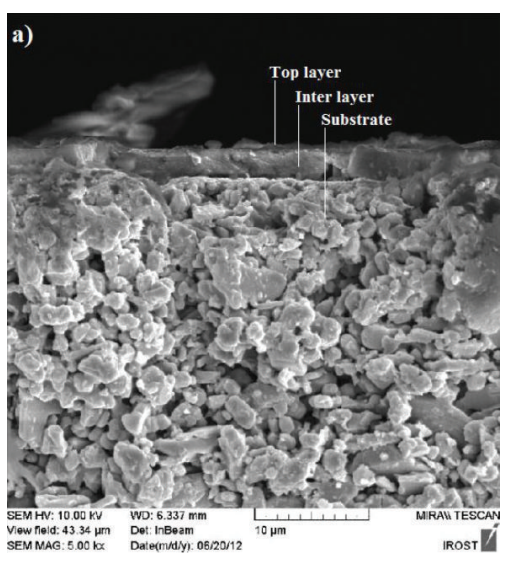

(a)

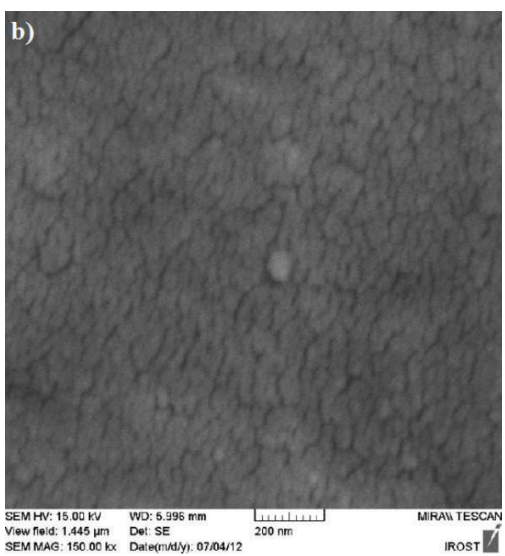

(b)

FIGURE 12: FESEM micrographs of (a) cross-section and (b) top surface of the synthesized anatase membrane.
The surface plot shows that the prepared anatase membrane has rough surface consisting of interconnected granular particles. As revealed by AFM, the membrane top layer shows the pores in the range of $20-200 \mathrm{~nm}$ that is categorized in UF membranes group according to IUPAC. The high surface roughness of the synthesized anatase membrane allows a good ability to absorb photons for photocatalytic activity.

3.3.6. Nitrogen Adsorption and Desorption. $\mathrm{N}_{2}$ adsorption and desorption isotherms as well as $\mathrm{BJH}$ pore size distribution of the unsupported anatase membranes were obtained by BET method (see Figure 15).

As shown in Figure 15(a), $\mathrm{N}_{2}$ hysteresis loop closes at a relative pressure, $p / p_{0}$, of around 0.4 that it is associated with capillary condensation. The nature of adsorption isotherm displays a type IV adsorption isotherm with a hysteresis loop classified as type $\mathrm{H}_{2}$ according to IUPAC [33], showing that major fraction of the pores are in the mesopore region. The adsorption and desorption isotherms do not coincide over a certain region of external pressures. At low pressures, first an adsorbate monolayer is formed on the pore surface, which is followed by the multilayer formation. The concept of monolayer adsorption works only on the perfect planar surface. A real surface possesses some degree of roughness, which makes adsorption to progress not homogeneously. The amount of molecules adsorbed on the external sample surface is negligible in comparison to that on the pore wall. The onset of the hysteresis loop usually marks the beginning of the capillary condensation in the pores. At the external pressure corresponding to the upper closure point of the hysteresis loop, the pores are completely filled with liquid [34]. Based on this analysis, BET specific surface area, pore volume, and mean pore diameter of the unsupported anatase membrane were determined to be around $32.8 \mathrm{~m}^{2} / \mathrm{g}, 0.067 \mathrm{~cm}^{3} / \mathrm{g}$ and $8.1762 \mathrm{~nm}$, respectively. Figure 15(b) shows the BJH pore size distribution curve of the unsupported anatase membrane calculated from the adsorption curve. It is found that the anatase membrane has a relatively narrow pore distribution in the range of $1-9 \mathrm{~nm}$ with a maximum at around $3.55 \mathrm{~nm}$. According to IUPAC, pores in the range of $2-50 \mathrm{~nm}$ are categorized into mesopores [35]. The results obtained of BET method are summarized in Table 4.

Thus, based on BET analysis, the prepared anatase membranes are classified as mesoporous membranes.

3.3.7. Photocatalytic Properties. Photocatalytic activity of the nanostructured anatase mesoporous membranes was evaluated by the absorbance changes of $\mathrm{MO}$ aqueous solution under UV radiation after 30 minutes according to Figure 16.

The MO removal efficiency was estimated by applying the following:

$$
\text { Removal efficiency }(\%)=\left[\frac{\left(C_{0}-C\right)}{C}\right] \times 100,
$$

where $C_{0}$ is the original $\mathrm{MO}$ concentration and $C$ is the residual MO concentration in the feed solution [36]. So, the MO removal efficiency by the photocatalytic capability 


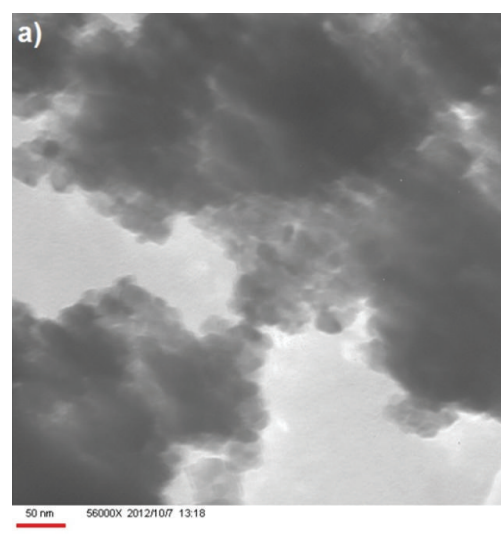

(a)

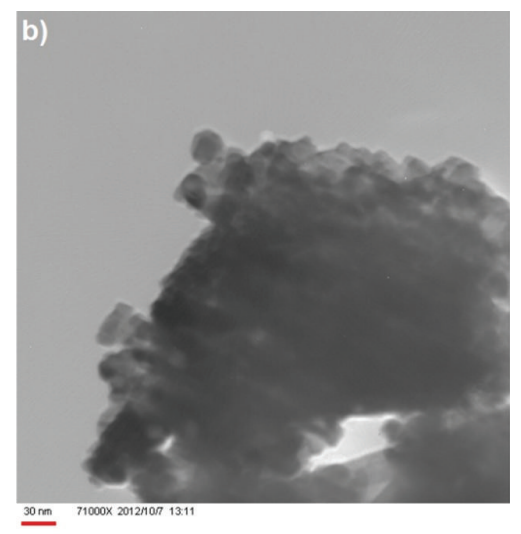

(b)

FIGURE 13: TEM micrographs of the membrane top layer.

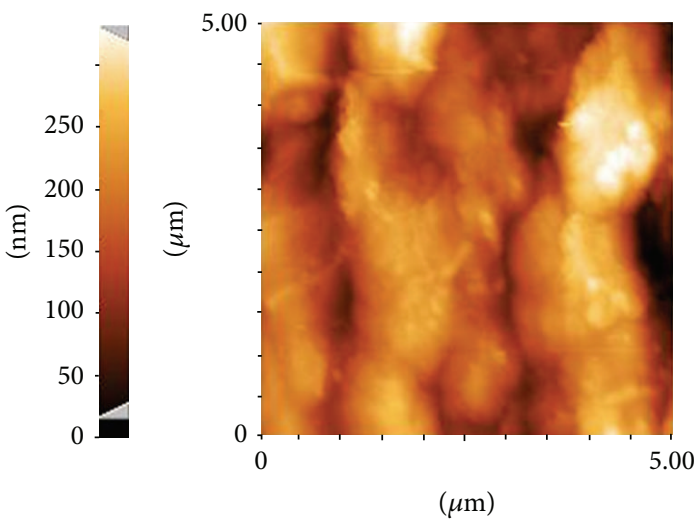

(a)

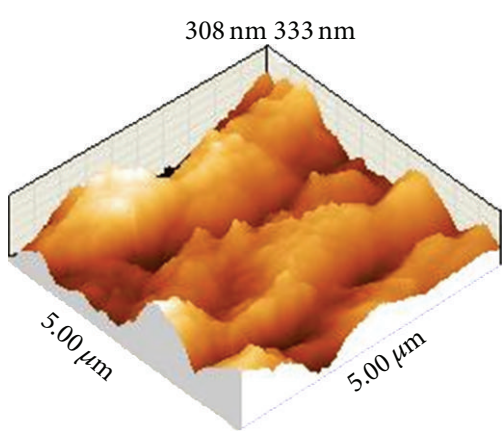

(b)

Figure 14: AFM micrographs (a) 2D and (b) 3D of the surface morphology of the nanostructured anatase membrane.

of the nanostructured anatase membranes was determined to be $61 \%$ after $30 \mathrm{~min}$ UV irradiation. It seems that the high roughness of membrane top layer (according to the AFM results in Figure 14) provides a better ability to capture the incident photon energy since a larger surface extension facilitates the photodegradation process. In fact, this surface not only enables the adsorption of a greater number of pollutant molecules but also creates a rough environment that causes a multiple light reflection and thus increases the amount of absorbed photons for photodegradation.

3.4. Membrane Experiments. The physical separation capability of the prepared anatase membranes was evaluated by direct measurement of $\mathrm{MO}$ concentration in the feed solution after passing through membrane at 5-bar pressure in constant time (see Figure 2). Figure 17 compares concentration of MO solution after passing through the membrane substrate, interlayer, and top layer.

Based on physical separation capability, the MO removal efficiency in the presence of alumina substrate, interlayer, and top layer was determined to be $4 \%, 20 \%$, and $52 \%$, respectively.
TABLE 4: The properties of the unsupported anatase membrane obtained of BET analysis.

\begin{tabular}{lccc}
\hline $\begin{array}{l}\text { Specific surface } \\
\text { area }\left(\mathrm{m}^{2} / \mathrm{g}\right)\end{array}$ & $\begin{array}{c}\text { Total pore } \\
\text { volume } \\
\left(\mathrm{cm}^{3} / \mathrm{g}\right)\end{array}$ & $\begin{array}{c}\text { Mean pore } \\
\text { diameter } \\
(\mathrm{nm})\end{array}$ & $\begin{array}{c}\text { Pore } \\
\text { distribution } \\
(\mathrm{nm})\end{array}$ \\
\hline 32.8 & 0.067 & 8.1762 & $1-9$ \\
\hline
\end{tabular}

Moreover, permeation flux in the presence of the membrane substrate, interlayer, and top layer was measured under 5 -bar pressure according to (1) that the results are seen in Figure 18.

According to Figure 18, the alumina substrate shows a high permeability, while permeability considerably decreases in the presence of interlayer with $2.5 \mu \mathrm{m}$ thickness. Moreover, the results indicate that depositing the top layer with $0.5 \mu \mathrm{m}$ thickness on the interlayer has a small effect on the permeability reduction. Based on this experiment, the permeation flux was calculated to be 1470,1069 , and $935 \mathrm{~cm}^{3} / \mathrm{hm}^{3}$ for the membrane substrate, interlayer, and top layer, respectively. The decreasing permeation flux can be attributed to the reduction of pores size. Permeation experiment is one of 


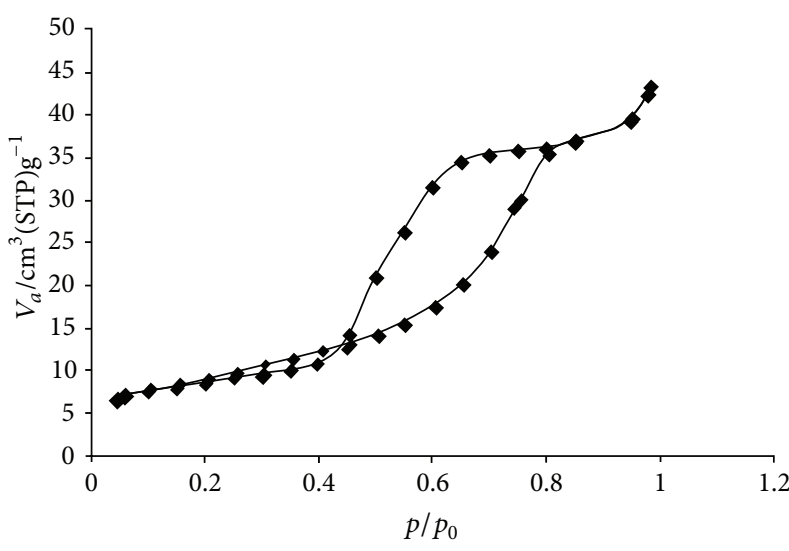

(a)

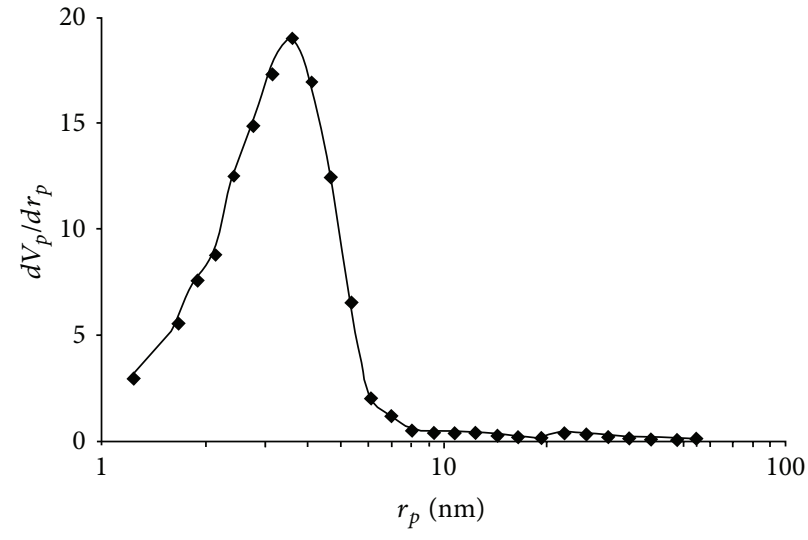

(b)

FIGURE 15: (a) The results obtained by BET method: $\mathrm{N}_{2}$ adsorption and desorption isotherms and (b) BJH pore diameter distribution of the unsupported anatase membrane.

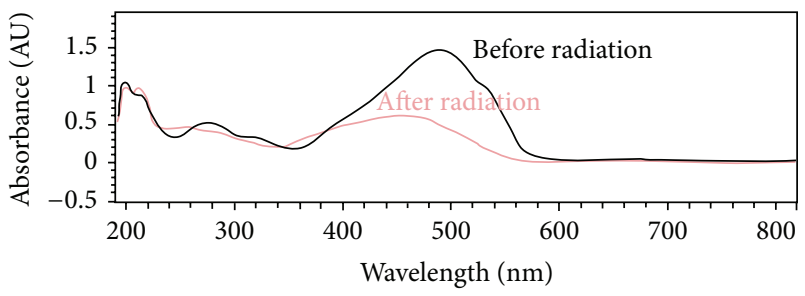

FIGURE 16: Absorbance curves of $\mathrm{MO}$ aqueous solution in the presence of the anatase membrane before and after UV radiation.

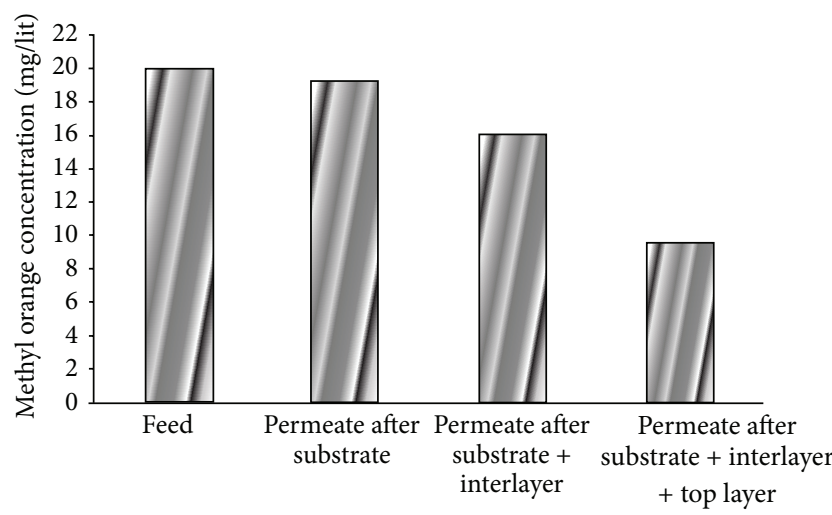

FIGURE 17: Concentration changes of MO solution before and after passing through the membrane substrate, interlayer, and top layer.

the most important methods for finding the structure and morphology of prepared membranes. Permeation flux is obviously affected by membrane structure and subsequently by preparation variables [37].

By coupling physical separation with photocatalytic technique, the MO removal efficiency was remarkably improved up to $83 \%$, while it was $61 \%$ and $52 \%$ with individual photocatalysis and separation techniques, respectively. Figure 19 compares $\mathrm{MO}$ removal efficiency by the different techniques using the anatase mesoporous membrane.

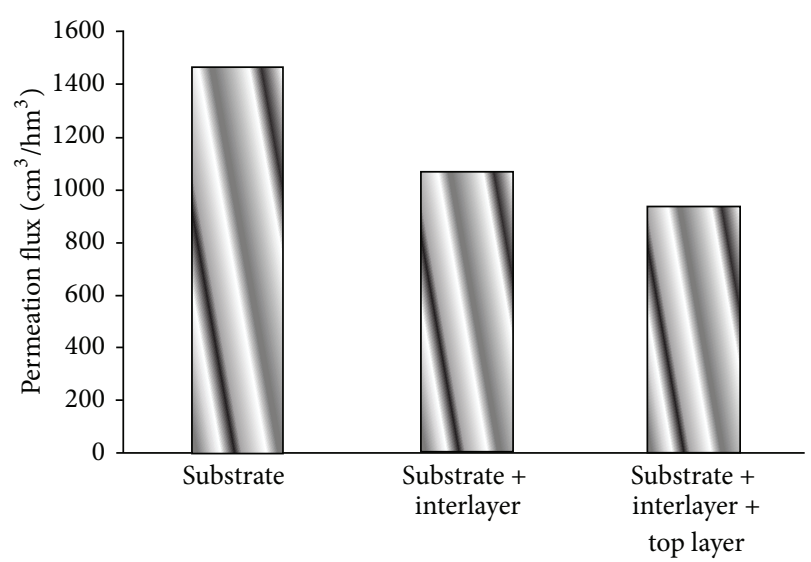

FIGURE 18: Permeation flux in the presence of substrate, substrate + interlayer and substrate + interlayer + toplayer.

As observed, the anatase membrane synthesized in this work showed a high potential due to its multifunctional capability consisting of photodegradation and physical separation in water purification process.

\section{Conclusion}

In this research, the nanostructured anatase mesoporous membranes were prepared for water UF process with photocatalytic and physical separation capabilities. A colloidal titania sol was deposited on $\alpha-\mathrm{Al}_{2} \mathrm{O}_{3}$ substrates as the membrane interlayer. Also, membrane top layer was synthesized by deposition and calcination of titania polymeric sol on the intermediate layer. The mean particle size of the colloidal and polymeric titania sols was determined to be 14 and $1.5 \mathrm{~nm}$, respectively. The synthesized anatase membranes exhibited homogeneity, with the surface area of $32.8 \mathrm{~m}^{2} / \mathrm{g}$, the maximum pore volume of $0.067 \mathrm{~cm}^{3} / \mathrm{g}$, the mean pore size of $8.17 \mathrm{~nm}$, and the crystallite size of $9.6 \mathrm{~nm}$. The removal efficiency of methyl orange based on physical separation 


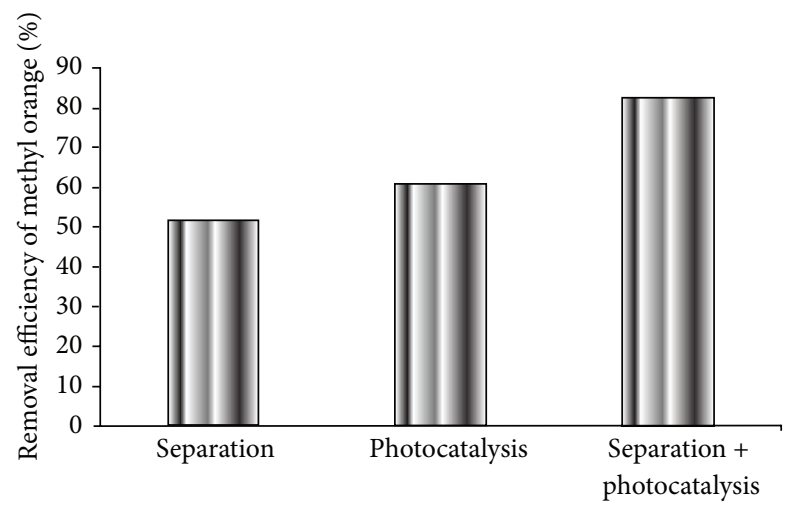

FIGURE 19: MO removal efficiency in the presence of anatase membrane by the different techniques.

by the mesoporous anatase membrane was determined to be $52 \%$ that by coupling photocatalytic technique, it was improved up to $83 \%$. Thus, the prepared UF membranes showed a high potential due to its multifunctional capability such as photodegradation and physical separation for water purification applications.

\section{Conflict of Interests}

The authors have no conflict of interests in relation with the instrumental companies directly or indirectly.

\section{References}

[1] C. C. Liu, Y. H. Hsieh, P. F. Lai, C. H. Li, and C. L. Kao, "Photodegradation treatment of azo dye wastewater by $\mathrm{UV} / \mathrm{TiO}_{2}$ process," Dyes and Pigments, vol. 68, no. 2-3, pp. 191-195, 2006.

[2] Q. Wang, D. Gao, Ch. Gao et al., "Removal of a cationic dye by adsorption/photodegradation using electrospun PAN/OMMT composite nanofibrous membranes coated with $\mathrm{TiO}_{2}$," International Journal of Photoenergy, vol. 2012, Article ID 680419, 8 pages, 2012.

[3] X. Huang, M. Leal, and Q. Li, "Degradation of natural organic matter by $\mathrm{TiO}_{2}$ photocatalytic oxidation and its effect on fouling of low-pressure membranes," Water Research, vol. 42, no. 4-5, pp. 1142-1150, 2008.

[4] B. S. Karnik, S. H. R. Davies, K. C. Chen, D. R. Jaglowski, M. J. Baumann, and S. J. Masten, "Effects of ozonation on the permeate flux of nanocrystalline ceramic membranes," Water Research, vol. 39, no. 4, pp. 728-734, 2005.

[5] N. Ma, X. Quan, Y. Zhang, S. Chen, and H. Zhao, "Integration of separation and photocatalysis using an inorganic membrane modified with $\mathrm{Si}$-doped $\mathrm{TiO}_{2}$ for water purification," Journal of Membrane Science, vol. 335, no. 1-2, pp. 58-67, 2009.

[6] W. Xin, D. Zhu, G. Liu, Y. Hua, and W. Zhou, "Synthesis and characterization of $\mathrm{Mn}$-C-Co doped $\mathrm{TiO}_{2}$ nanoparticles and photocatalytic degradation of methyl orange dye under sunlight irradiation," International Journal of Photoenergy, vol. 2012, Article ID 767905, 7 pages, 2012.

[7] A. Alem, H. Sarpoolaky, and M. Keshmiri, "Titania ultrafiltration membrane: preparation, characterization and photocatalytic activity," Journal of the European Ceramic Society, vol. 29, no. 4, pp. 629-635, 2009.
[8] A. Alem, H. Sarpoolaky, and M. Keshmiri, "Sol-gel preparation of titania multilayer membrane for photocatalytic applications," Ceramics International, vol. 35, no. 5, pp. 1837-1843, 2009.

[9] S. H. Hyun and B. S. Kang, "Synthesis of titania composite membranes by the pressurized sol-gel technique," Journal of the American Ceramic Society, vol. 79, no. 1, pp. 279-282, 1996.

[10] R. S. Sonawane, S. G. Hegde, and M. K. Dongare, "Preparation of titanium(IV) oxide thin film photocatalyst by sol-gel dip coating," Materials Chemistry and Physics, vol. 77, no. 3, pp. 744$750,2003$.

[11] J. Yu, M. Jaroniec, and G. $\mathrm{Lu}$, " $\mathrm{TiO}_{2}$ photocatalytic materials," International Journal of Photoenergy, vol. 2012, Article ID 206183, 5 pages, 2012.

[12] C. P. Athanasekou, G. E. Romanos, F. K. Katsaros, K. Kordatos, V. Likodimos, and P. Falarasa, "Very efficient composite titania membranes in hybrid ultrafiltration/photocatalysis water treatment processes," Journal of Membrane Science, vol. 392-393, pp. 192-203, 2012.

[13] H. Choi, E. Stathatos, and D. D. Dionysiou, "Photocatalytic $\mathrm{TiO}_{2}$ films and membranes for the development of efficient wastewater treatment and reuse systems," Desalination, vol. 202, no. 1-3, pp. 199-206, 2007.

[14] A. L. Castro, M. R. Nunes, A. P. Carvalho, F. M. Costa, and M. H. Florêncio, "Synthesis of anatase $\mathrm{TiO}_{2}$ nanoparticles with high temperature stability and photocatalytic activity," Solid State Sciences, vol. 10, no. 5, pp. 602-606, 2008.

[15] L. Djafer, A. Ayral, and A. Ouagued, "Robust synthesis and performance of a titania-based ultrafiltration membrane with photocatalytic properties," Separation and Purification Technology, vol. 75, no. 2, pp. 198-203, 2010.

[16] C. He, B. Tian, and J. Zhang, “Thermally stable $\mathrm{SiO}_{2}$-doped mesoporous anatase $\mathrm{TiO}_{2}$ with large surface area and excellent photocatalytic activity," Journal of Colloid and Interface Science, vol. 344, no. 2, pp. 382-389, 2010.

[17] L. Caldeira, D. C. L. Vasconcelos, E. H. M. Nunes et al., "Processing and characterization of sol-gel titania membranes," Ceramics International, vol. 38, no. 4, pp. 3251-3260, 2012.

[18] M. Sivakumar, D. R. Mohan, and R. Rangarajan, "Studies on cellulose acetate-polysulfone ultrafiltration membranes: II. Effect of additive concentration," Journal of Membrane Science, vol. 268, no. 2, pp. 208-219, 2006.

[19] T. Tsuru, D. Hironaka, T. Yoshioka, and M. Asaeda, “Titania membranes for liquid phase separation: effect of surface charge on flux," Separation and Purification Technology, vol. 25, no. 1-3, pp. 307-314, 2001.

[20] T. van Gestel, C. Vandecasteele, A. Buekenhoudt et al., "Alumina and titania multilayer membranes for nanofiltration: preparation, characterization and chemical stability," Journal of Membrane Science, vol. 207, no. 1, pp. 73-89, 2002.

[21] W. J. Koros, Y. H. Ma, and T. Shimidzu, "Terminology for membranes and membrane process," IUPAC, Comission on membrane nomenclature, 1995.

[22] K. G. K. Warrier, S. R. Kumar, C. P. Sibu, and G. Werner, "High temperature stabilisation of pores in sol-gel titania in presence of silica," Journal of Porous Materials, vol. 8, no. 4, pp. 311-317, 2001.

[23] S. Mayadevi, S. S. Kulkarni, A. J. Patil et al., "Controlled chemical precipitation of titania for membrane applicationseffect of heat treatment and fabrication conditions on its performance," Journal of Materials Science, vol. 35, no. 15, pp. 3943-3949, 2000. 
[24] A. Kermanpur, E. Ghassemali, and S. Salemizadeh, "Synthesis and characterisation of microporous titania membranes by dipcoating of anodised alumina substrates using sol-gel method," Journal of Alloys and Compounds, vol. 461, no. 1-2, pp. 331-335, 2008.

[25] S. Mozia, A. W. Morawski, M. Toyoda, and M. Inagaki, "Application of anatase-phase $\mathrm{TiO}_{2}$ for decomposition of azo dye in a photocatalytic membrane reactor," Desalination, vol. 241, no. 1-3, pp. 97-105, 2009.

[26] V. T. Zaspalis, W. van Praag, K. Keizer, J. R. H. Ross, and A. J. Burggraaf, "Synthesis and characterization of primary alumina, titania and binary membranes," Journal of Materials Science, vol. 27, no. 4, pp. 1023-1035, 1992.

[27] J. L. Zhang, W. Li, X. K. Meng, L. Wang, and L. Zhu, "Synthesis of mesoporous silica membranes oriented by self-assembles of surfactants," Journal of Membrane Science, vol. 222, no. 1-2, pp. 219-224, 2003.

[28] A. A. Habibpanah, S. Pourhashem, and H. Sarpoolaky, "Preparation and characterization of photocatalytic titania-alumina composite membranes by sol-gel methods," Journal of the European Ceramic Society, vol. 31, no. 15, pp. 2867-2875, 2011.

[29] J. Sekulić Kuzmanović, Mesoporous and microporous titania membranes [Ph.D. thesis], 2004.

[30] B. D. Cullity, Elements of X-Ray Diffraction, Addison-Wesley, Reading, Mass, USA, 1978.

[31] Zh. Li, B. Hou, Y. Xu et al., "Comparative study of sol-gelhydrothermal and sol-gel synthesis of titania-silica composite nanoparticles," Journal of Solid State Chemistry, vol. 178, no. 5, pp. 1395-1405, 2005.

[32] F. Bosc, A. Ayral, P. A. Albouy, and C. Guizard, "A simple route for low-temperature synthesis of mesoporous and nanocrystalline anatase thin films," Chemistry of Materials, vol. 15, no. 12, pp. 2463-2468, 2003.

[33] K. S. W. Sing, D. H. Everett, R. A. W. Haul et al., "Reporting physisorption data for gas/solid systems with special reference to the determination of surface area and porosity," Pure and Applied Chemistry, vol. 57, no. 4, pp. 603-619, 1985.

[34] S. Naumov, Hysteresis phenomena in mesoporous materials [Dissertation], Universitat Leipzig, 2009.

[35] T. Tsuru, "Nano/subnano-tuning of porous ceramic membranes for molecular separation," Journal of Sol-Gel Science and Technology, vol. 46, no. 3, pp. 349-361, 2008.

[36] A. A. Ismail, I. A. Ibrahim, M. S. Ahmed, R. M. Mohamed, and H. El-Shall, "Sol-gel synthesis of titania-silica photocatalyst for cyanide photodegradation," Journal of Photochemistry and Photobiology A, vol. 163, no. 3, pp. 445-451, 2004.

[37] E. Saljoughi, M. Sadrzadeh, and T. Mohammadi, "Effect of preparation variables on morphology and pure water permeation flux through asymmetric cellulose acetate membranes," Journal of Membrane Science, vol. 326, no. 2, pp. 627-634, 2009. 

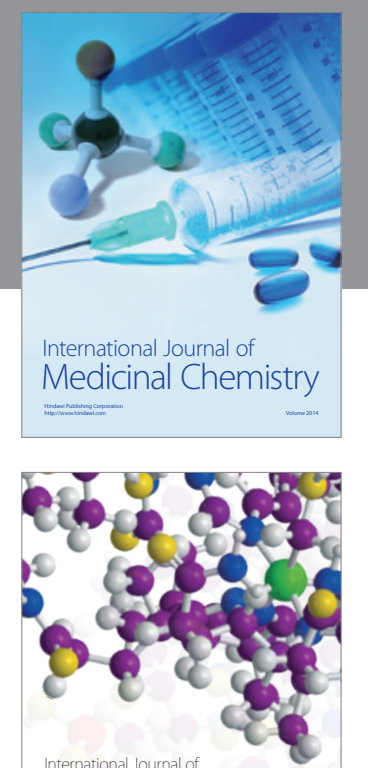

\section{Carbohydrate} Chemistry

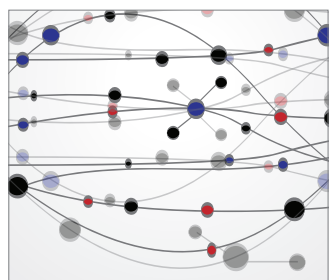

The Scientific World Journal
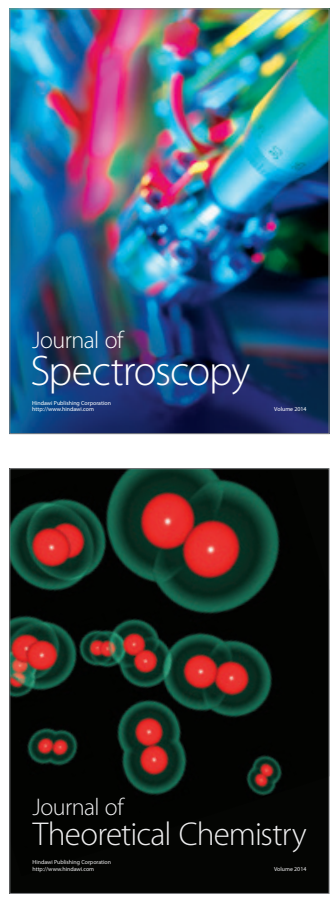
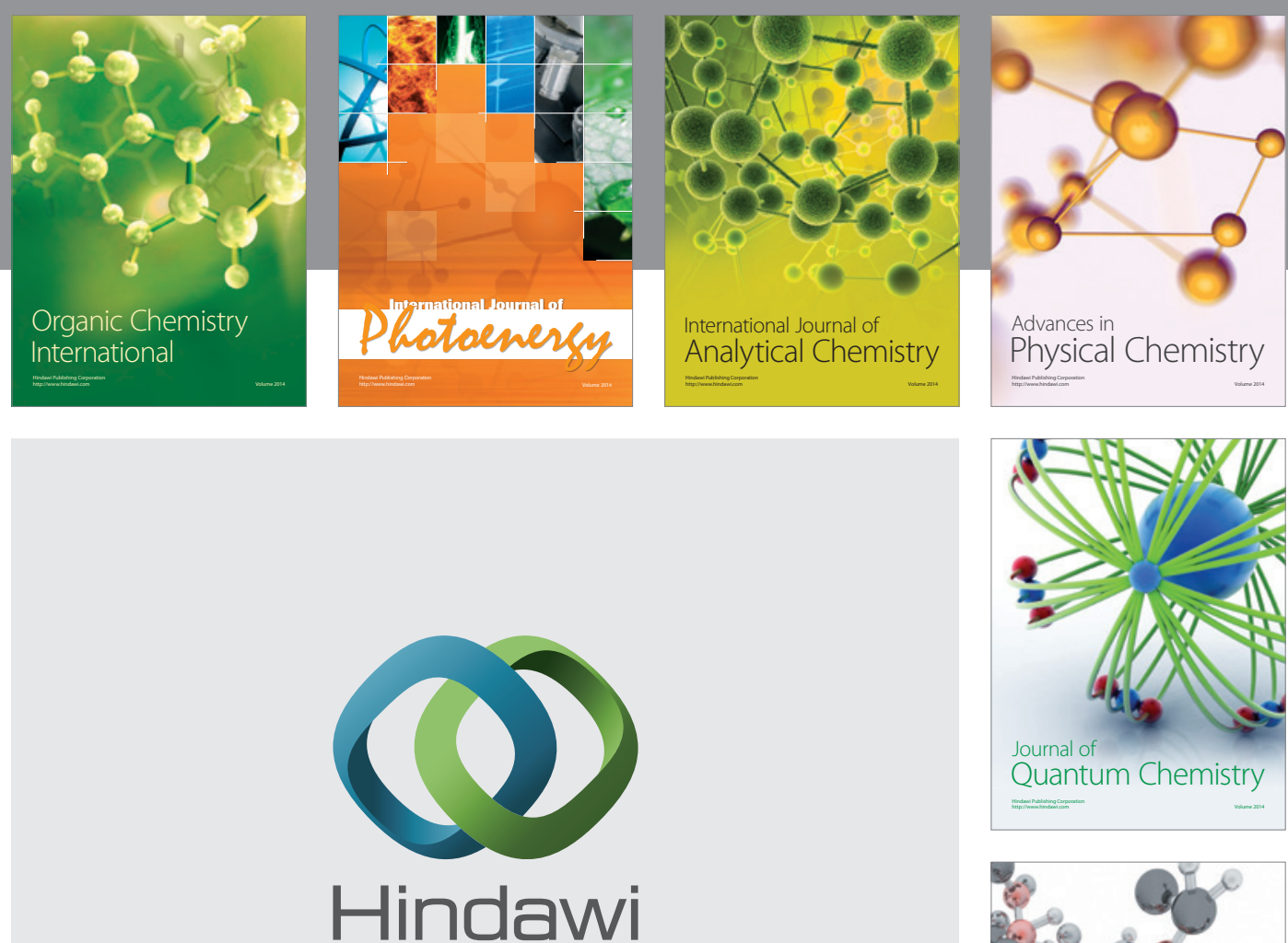

Submit your manuscripts at

http://www.hindawi.com

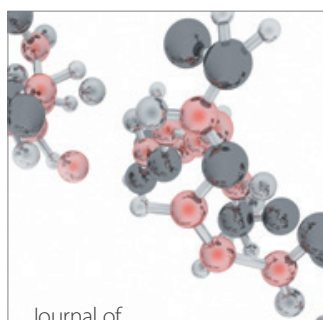

Analytical Methods

in Chemistry

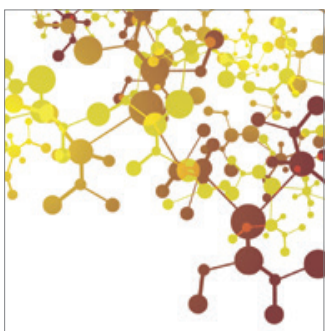

Journal of

Applied Chemistry

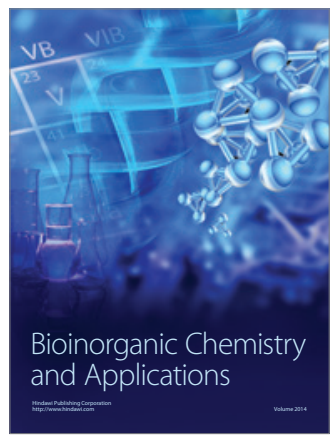

Inorganic Chemistry
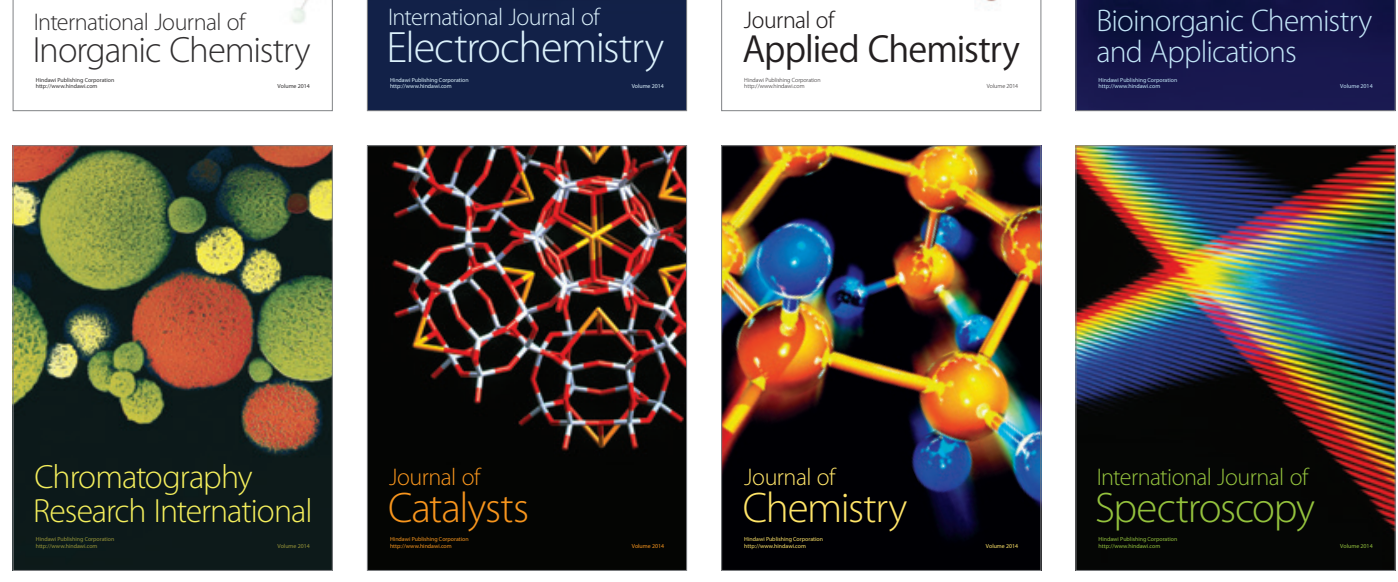